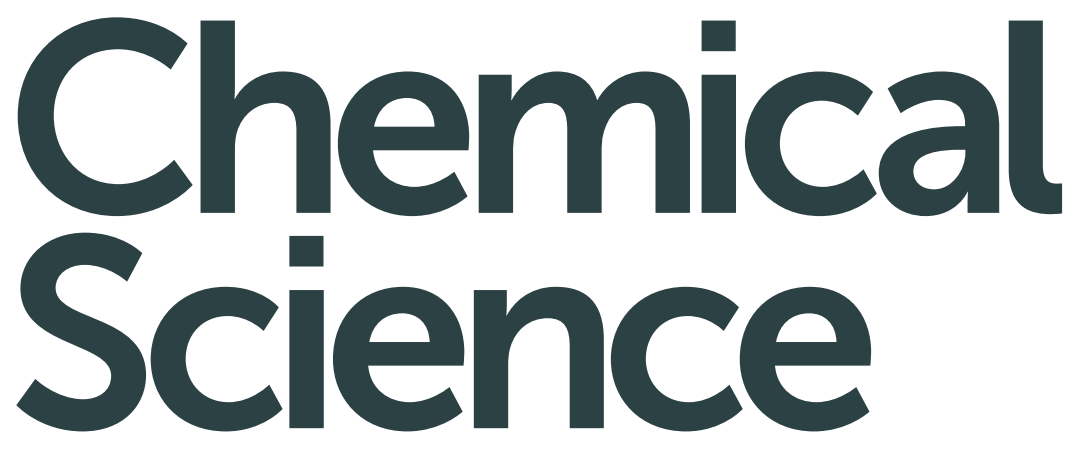

rsc.li/chemical-science

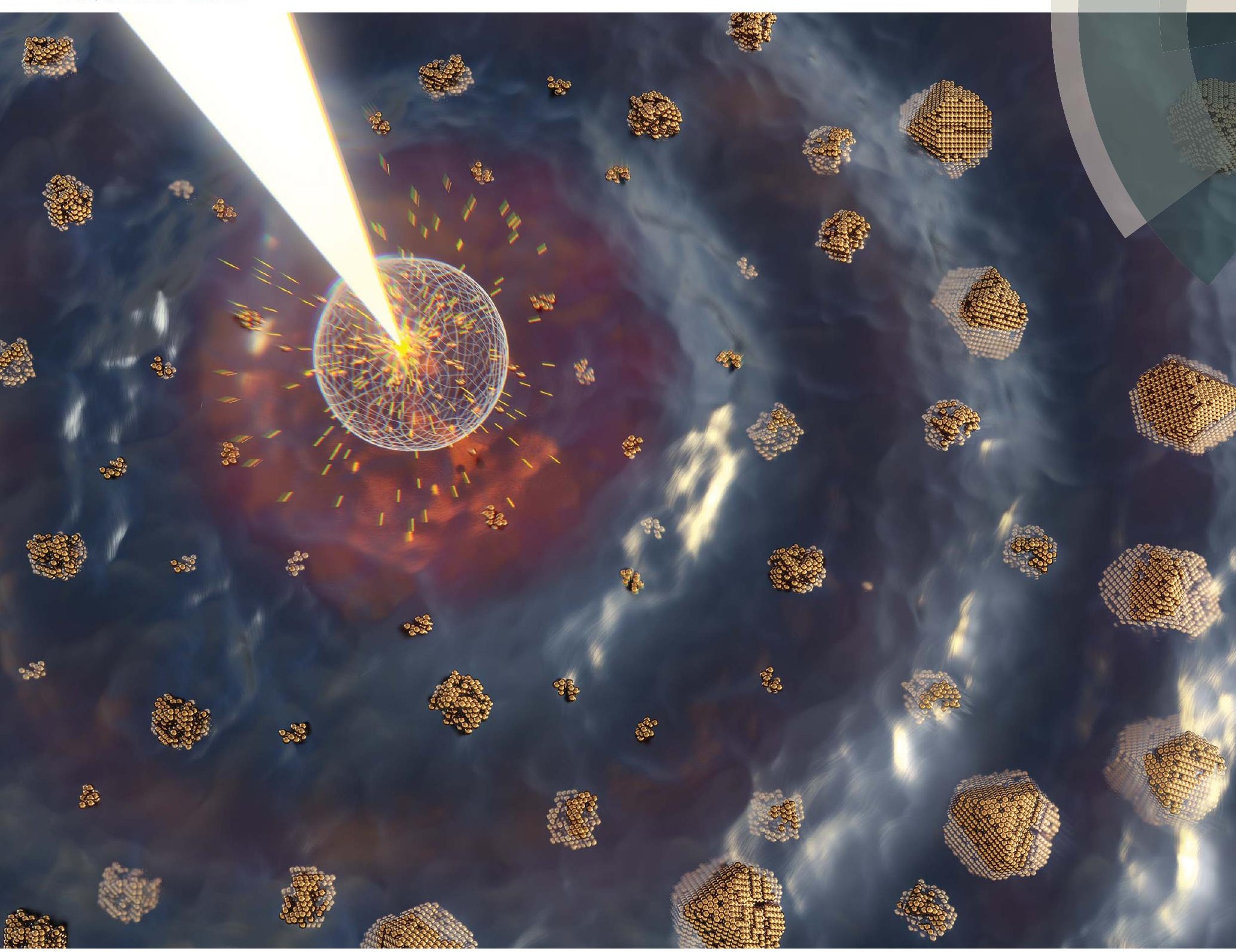

ISSN 2041-6539

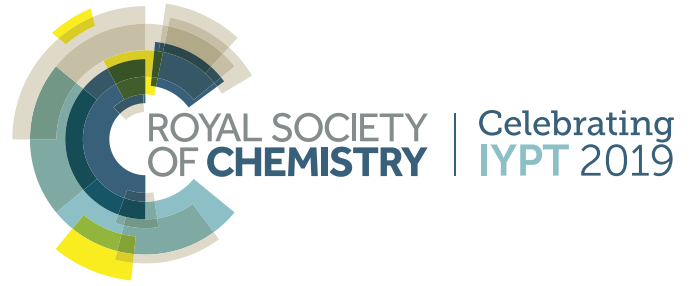


Check for updates

Cite this: Chem. Sci., 2019, 10, 8735

๑ All publication charges for this article have been paid for by the Royal Society of Chemistry

Received 7th May 2019

Accepted 14th August 2019

DOI: $10.1039 / c 9 s c 02227 a$

rsc.li/chemical-science

\section{Controlling the radical-induced redox chemistry inside a liquid-cell TEM $\uparrow$}

\author{
Bojan Ambrožič, (D) $\ddagger^{a b}$ Anže Prašnikar, (D) $\Psi^{c}$ Nejc Hodnik, (D) ${ }^{c}$ Nina Kostevšek, (D) ${ }^{a}$ \\ Blaž Likozar, (D) Kristina Žužek Rožman (iD a and Sašo Šturm (iD *a
}

With Liquid-Cell Transmission Electron Microscopy (LCTEM) we can observe the kinetic processes taking place in nanoscale materials that are in a solvated environment. However, the beam-driven solvent radiolysis, which results from the microscope's high-energy electron beam, can dramatically influence the dynamics of the system. Recent research suggests that radical-induced redox chemistry can be used to investigate the various redox-driven dynamics for a wide range of functional nanomaterials. In view of this, the interplay between the formation of various highly reactive radiolysis species and the nanomaterials under investigation needs to be quantified in order to formulate new strategies for nanomaterials research. We have developed a comprehensive radiolysis model by using the electrondose rate, the temperature of the solvent, the $\mathrm{H}_{2}$ and $\mathrm{O}_{2}$ gas saturation concentrations and the $\mathrm{pH}$ values as the key variables. These improved kinetic models make it possible to simulate the material's specific radical-induced redox reactions. As in the case of the Au model system, the kinetic models are presented using Temperature/Dose-rate Redox potential (TDR) diagrams, which indicate the equilibrium $\left[\mathrm{Au}^{0}\right] /\left[\mathrm{Au}^{+}\right]$concentration ratios that are directly related to the temperature-/dose-rate-dependent precipitation or dissolution regions of the Au nanoparticles. Our radiolysis and radical-induced redox models were successfully verified using previously reported data from low-dose experiments with $\gamma$ radiation and experimentally via TDR-dependent LCTEM. The presented study represents a holistic approach to the radical-induced redox chemistry in LCTEM, including the complex kinetics of the radiolysis species and their influence on the redox chemistry of the materials under investigation, which are represented here by Au nanoparticles.

\section{Introduction}

A transmission electron microscope (TEM) allows the direct imaging and spectroscopy of nanoparticles (NPs). The TEM is conventionally operated in a high vacuum, which requires the samples to be dehydrated. Recent advances have partially overcome this limitation with the use of specialized TEM harnesses, i.e., liquid cells, that can maintain the liquid in a closed environment, allowing the imaging and spectroscopy of samples in liquid media without affecting the vacuum in the

aJožef Stefan Institute, Department for Nanostructured Materials, Jamova 39, Ljubljana, Slovenia. E-mail: saso.sturm@ijs.si

${ }^{b} J o z ̌ e f$ Stefan International Postgraduate School, Jamova 39, Ljubljana, Slovenia ${ }^{c}$ National Institute of Chemistry, Department of Catalysis and Chemical Reaction Engineering, Hajdrihova 19, Ljubljana, Slovenia

$\dagger$ Electronic supplementary information (ESI) available: General model description of the water radiolysis, reaction rates and $G$-values. Estimation of the reaction-rate constants of the water radiolysis products with gold species. Sensitivity analysis of the temperature-dependent part of the $\mathrm{H}_{2}$ and $\mathrm{O}_{2}$ solubility. Model details for the verification by low-dose experiments using $\gamma$ radiation. Ex situ SAED analysis of the conformation of gold NPs. See DOI: 10.1039/c9sc02227a

\$ B. A. and A. P. contributed equally. microscope. ${ }^{1}$ The samples are held between two silicon chips that have electron-transparent windows made from silicon nitride $^{2}$ or graphene. ${ }^{3}$ This allows us to study dynamic phenomena taking place in the materials in solvated environments ${ }^{4}$ with high spatial and temporal resolution..$^{5,6}$

Several previous studies were focused on the precipitation and dissolution dynamics of different nanostructured systems utilizing electron-beam-induced phenomena inside a liquid-cell TEM, for example, $\mathrm{Cu}$ and $\mathrm{Ni}$ nanocrystals, ${ }^{7} \mathrm{Pd}$ dendritic nanostructures, ${ }^{8}$ alloys such as $\mathrm{Ag}-\mathrm{Pd}^{7}$ or more complex structures like $\mathrm{CaCO}_{3}$ (ref. 9) and $\mathrm{CeO}_{2} \cdot{ }^{10}$ One of the most commonly studied materials using the liquid-cell electron-microscopy (LCTEM) technique is gold, ${ }^{\mathbf{1 1}-\mathbf{1 4}}$ with the aim being to investigate the dynamics of the precipitation and dissolution of $\mathrm{Au}$ NPs in various aqueous environments. The findings revealed a complex interplay of thermodynamic and kinetic parameters that influence the final morphologies, begging questions about the influence of electron-beam-induced phenomena. ${ }^{11,12,15-21}$

Dynamic LCTEM has tremendous potential when it comes to probing and understanding the underlying mechanisms of nucleation and the early growth stages of nanomaterials. ${ }^{9,16}$ On the other hand, there are major challenges related to the 
interaction effects between the electron beam and the solvent, which can modify the reaction kinetics to such an extent that they can no longer be directly related to the experiments. ${ }^{21}$ It is well documented that these effects are the result of water radiolysis due to the interaction between water and the energyintense $(80-300 \mathrm{keV})$ electron beam. ${ }^{2-24}$ Here, radiolysis is defined as the electron-beam-induced degradation of a waterbased electrolyte as a consequence of inelastic scattering. ${ }^{18,25}$ There are three separate stages of this radiolysis: the physical stage, which lasts up to $10^{-15} \mathrm{~s}$, the physicochemical stage, which dominates between $10^{-15}$ and $10^{-12} \mathrm{~s}$, and the chemical stage, taking place for time scales longer than $10^{-12} \mathrm{~s}$. We focused on the chemical stage after $10^{-6} \mathrm{~s}$, where the radiolysis species are considered to be homogeneously distributed. Several types of reactions occur in this stage: reactions between different radiolysis species, reactions between radiolysis species and gases, and reactions between the radiolysis and the Au species.

Fifteen radiolytic species are known to form in water: solvated electrons $\left(\mathrm{e}_{\mathrm{aq}}{ }^{-}\right)$, hydrogen radicals $\left(\mathrm{H}^{*}\right)$, hydroxyl radicals $\left(\mathrm{OH}^{*}\right)$, hydrogen $\left(\mathrm{H}_{2}\right)$, hydrogen peroxide $\left(\mathrm{H}_{2} \mathrm{O}_{2}\right)$, hydroperoxyl radicals $\left(\mathrm{HO}_{2}{ }^{\circ}\right)$, hydroperoxyls $\left(\mathrm{HO}_{2}{ }^{-}\right)$, protons $\left(\mathrm{H}^{+}\right)$, oxygen $\left(\mathrm{O}_{2}\right)$, superoxides $\left(\mathrm{O}_{2}{ }^{-}\right)$, oxygen anions $\left(\mathrm{O}^{\cdot-}\right)$, ozone $\left(\mathrm{O}_{3}\right)$, hydrogen trioxy radicals $\left(\mathrm{HO}_{3}{ }^{\circ}\right)$, ozone anions $\left(\mathrm{O}_{3}{ }^{-}\right)$, and hydroxide $\left(\mathrm{OH}^{-}\right)$. Of these, the most reactive components are the reducing solvated electrons $\left(\mathrm{e}_{\mathrm{aq}}{ }^{-}\right)$with a very negative standard redox potential of $E^{0}=-2.90 \mathrm{~V}_{\mathrm{SHE}}$ (ref. 26) and the hydroxyl radicals $\left(\mathrm{OH}^{*}\right)$ that act as a strong oxidizing agent $\left(E^{0}=+1.8 \mathrm{~V}_{\mathrm{SHE}}\right.$ (ref. 27)). Consequently, the overall chemical reactions between the radiolytic species and the sample during the LCTEM need to be resolved before we can make any reliable interpretation of the experimental data. Schneider $e t a l .{ }^{11}$ were the first to quantify this very complex process inside the liquid cell using a radiolysis model to predict the concentration of the radiolysis species as a function of the dose rate. Although the direct imaging of the radiolysis species is not possible in LCTEM, their presence can be, to some extent, detected by indirect approaches. For example, by quantifying the nucleation and dissolution of $\mathrm{Au}$ NPs as a function of the equilibrium concentration ratios of the radiolysis products that act as oxidizing and reducing species, ${ }^{11}$ by using silver NPs as a calibration standard to quantify the effect of the dose rate (as a silver precursor is known to follow a simple, one-electron reduction reaction), ${ }^{18}$ or by observing the formation of a gas bubble inside the liquid cell. ${ }^{22}$

We are proposing a holistic approach that goes well beyond the existing radiolysis models ${ }^{\mathbf{1 1}}$ and will allow us to predict the radical-induced redox chemistry inside a liquid-cell TEM and so design and control the growth of nanostructures. The new kinetic radical-induced redox model considers the following parameters: electron-dose rate, temperature, the formation of $\mathrm{H}_{2}$ and $\mathrm{O}_{2}$ gaseous phases and the initial $\mathrm{pH}$. Until now, radiolysis models did not include the reactant species with their rate constants and were thus limited to a qualitative assessment of the nanomaterials' precipitation/dissolution kinetics. In our new radiolysis model, where radical-induced redox chemistry is included, the equilibrium concentration of $\mathrm{Au}$ ions, $\left[\mathrm{Au}^{+}\right]$, and solid $\mathrm{Au},\left[\mathrm{Au}^{0}\right]$, is included in the model like any other species. The experimental conditions that were used for the gold precipitation and dissolution are in accordance with several previously performed LCTEM investigations, ${ }^{2,6,11,13,28}$ allowing us to make a direct comparison. With more detailed knowledge of the radical-induced redox mechanisms, our model offers better control over the experimental conditions in the liquidcell TEM, which can now be controlled to influence the properties of material systems.

\section{Results and discussion}

\section{The description of the kinetic radical-induced redox model for gold}

This section presents an overview of the calculation for the kinetic radical-induced redox model. The details of the chemical kinetics, the reaction-rate constants, the primary yields and the evaluation of various model parameters, which are experimentally difficult to assess, are included in the ESI. $\dagger$

The temperature-/dose-rate-dependent kinetic waterradiolysis model consists of reactions between the Au and the radiolytic species, being valid in the temperature range 20$100{ }^{\circ} \mathrm{C}$ for acidic and neutral initial solutions. For clarity, the calculated diagrams that are compared with the LCTEM are shown in the same temperature range of $20-60{ }^{\circ} \mathrm{C}$, matching the experimental conditions. The model includes the following species: $\mathrm{e}_{\mathrm{aq}}{ }^{-}, \mathrm{H}^{\circ}, \mathrm{OH}^{\cdot}, \mathrm{H}_{2}, \mathrm{H}_{2} \mathrm{O}_{2}, \mathrm{HO}_{2}{ }^{\circ}, \mathrm{HO}_{2}{ }^{-}, \mathrm{H}^{+}, \mathrm{O}_{2}, \mathrm{O}_{2}{ }^{--}$and $\mathrm{OH}^{-}$. Other species $\left(\mathrm{O}^{\cdot-}, \mathrm{O}_{3}, \mathrm{HO}_{3}{ }^{\circ}, \mathrm{O}_{3}{ }^{\circ}\right)$ were not included in the model due to their low concentrations at neutral and low initial $\mathrm{pH}$ and the lack of reaction-rate constants. The validation of this simplification can be found in the ESI, Section 1.1. $\dagger$ The reaction-rate coefficients were taken from the literature ${ }^{29}$ and rewritten in the shape of the Arrhenius relationship. The primary yields, i.e., the $G$-values of the water radiolysis for the temperature range $20-100{ }^{\circ} \mathrm{C}$ were linearly interpolated from the tabulated $G$-values at $20{ }^{\circ} \mathrm{C}$ and $100{ }^{\circ} \mathrm{C},{ }^{29}$ respectively. The kinetic constants and more details about the calculation of the kinetic model can be found in the ESI, Section 1.1. $\dagger$

The kinetic model was further corrected to take into account the presence of the gaseous phase. A common phenomenon observed during LCTEM is the formation of gas bubbles, ${ }^{22,24,30,31}$ implying that the solubility of the formed gases in the liquid is exceeded during LCTEM. This is mainly due to the formation of molecular hydrogen and oxygen during the radiolysis.

For example, by comparing the calculated equilibrium concentrations of $\mathrm{H}_{2}$ and $\mathrm{O}_{2}$ dissolved in the aqueous solution with their corresponding saturation concentrations at the limiting pressure of 1 bar and in the temperature range 20$60{ }^{\circ} \mathrm{C}$, calculations predict the formation of a gas bubble already at dose rates higher than $10^{6} \mathrm{~Gy} \mathrm{~s}^{-1}$. The effect of window bulging, ${ }^{34,35}$ due to the presence of a differential pressure between the liquid in the cell and the vacuum in the TEM column can further decrease the initial cell pressure, which would provoke the gas-bubble formation even at lower dose rates. The lower pressure limit in the liquid-cell TEM is set by the water vapor pressure, which is around 0.02 bar at $20^{\circ} \mathrm{C}$. 
Fig. 1 shows the importance of gas-phase formation in the model, from two separate aspects. First, once the gas bubble is formed the equilibrium pressure due to the high concentration of $\mathrm{H}_{2}$ and $\mathrm{O}_{2}$ in the liquid cell can rise significantly and will continue to increase with an increased dose rate. The effect of a temporal pressure increase at different dose rates is emphasized in the ESI, Section 1.1 (Fig. S2 $\dagger$ ). Second, the formation of a thin liquid film $\left(d_{\mathrm{L}} \sim 50 \mathrm{~nm}\right.$ (ref. 22)) in real systems enables fast $\mathrm{O}_{2}$ and $\mathrm{H}_{2}$ transfer between the liquid and the gas in a period of $\mu$ s (inset figure). Due to the fast transfer rate between the gas and the liquid phase we assumed that the gas partial pressure and the dissolved $\mathrm{O}_{2}$ and $\mathrm{H}_{2}$ concentrations in the aqueous solution were in equilibrium. The temperaturedependent solubility values for $\mathrm{H}_{2}$ and $\mathrm{O}_{2}$ were obtained from $\mathrm{NIST}^{32,33}$ and the initial $\mathrm{pH}$ is set to 2.8 , assuming that all the liquid in the cell was evenly irradiated by the electron beam.

As the partial pressure of water only changes from $0.023 \mathrm{bar}$ at $20^{\circ} \mathrm{C}$ to 0.199 bar at $60^{\circ} \mathrm{C}$ we can assume that the influence of the water's partial pressure on the overall pressure in the gas phase is negligible. This suggests that the pressure increase in the closed cell is predominately controlled by the electron dose rate, which provokes the formation of $\mathrm{H}_{2}$ and $\mathrm{O}_{2}$ due to water radiolysis. It was experimentally confirmed that a liquid cell with similar dimensions can withstand a pressure of $4 \mathrm{bar}^{34}$ In practice, a large pressure increase is only expected at high dose rates, since only a small portion of the solution is irradiated by the electron beam. The pressure can also be partially compensated by bowing of the SiN window. ${ }^{35}$

Fig. 2 shows the equilibrium concentrations of the radiolysis products under typical LCTEM conditions for the Au system: a dose rate of $10^{7} \mathrm{~Gy} \mathrm{~s}^{-1}$ and an initial $\mathrm{pH}$ of 2.8 in the temperature range $20-60^{\circ} \mathrm{C}$. The equilibrium concentrations of the radiolysis species were calculated at two limiting pressures in the liquid cells, i.e., at 1 bar and 5 bar (Fig. 2). The pressuredependent differences in the equilibrium concentration of the radiolysis species are clearly visible (Fig. 2b). The

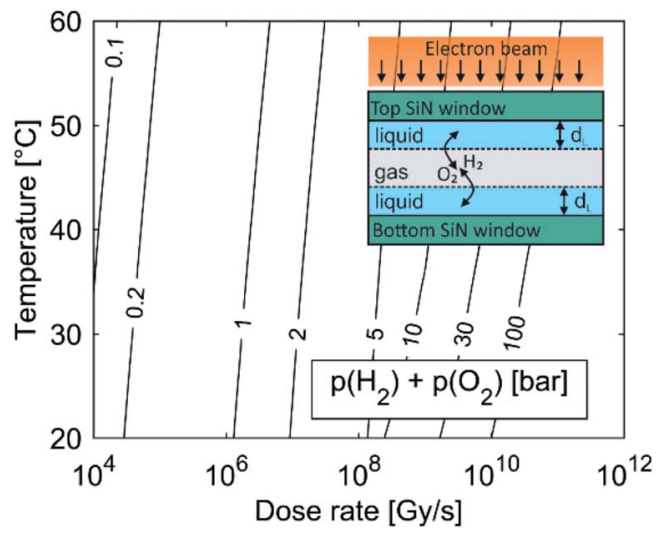

Fig. 1 Pressure due to dissolved $\mathrm{H}_{2}$ and $\mathrm{O}_{2}$ in the equilibrium state for the water-radiolysis simulation. The initial $\mathrm{pH}$ is set to 2.8 , with no initially dissolved $\mathrm{O}_{2}$ or $\mathrm{H}_{2}$. The inset shows a schematic representation of the LCTEM system with the gaseous phase. The liquid layer is very thin $\left(d_{\mathrm{L}} \sim 50 \mathrm{~nm}\right)$, allowing $\mathrm{O}_{2}$ and $\mathrm{H}_{2}$ transfer between the liquid and the gas in a period of $\mu$ s.
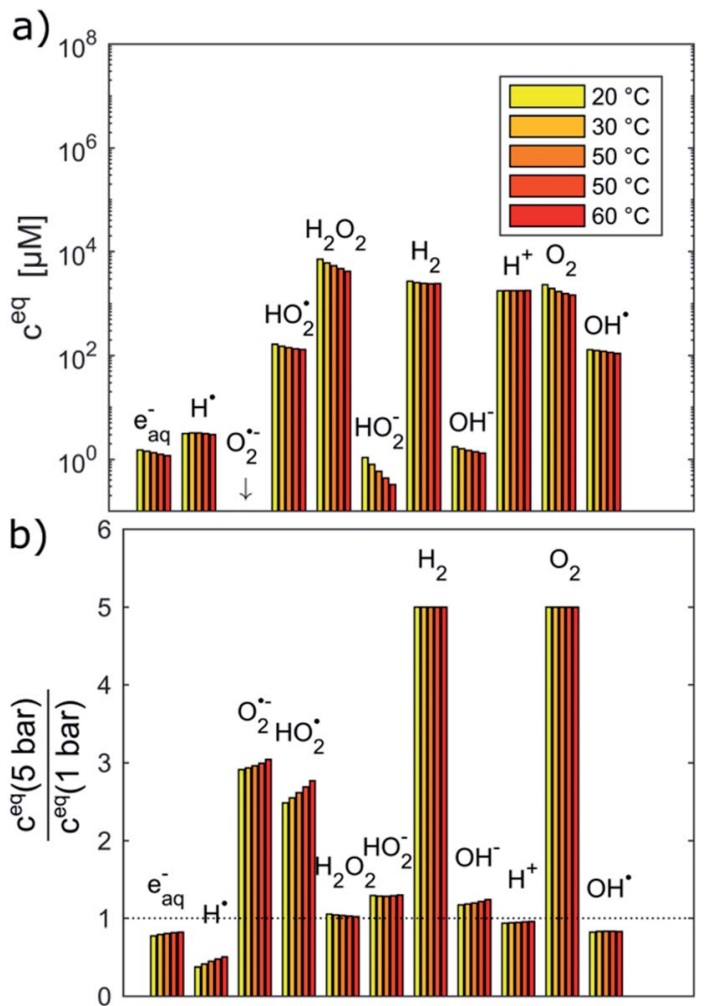

Fig. 2 Equilibrium concentrations of radiolysis species in water at a dose rate of $10^{7} \mathrm{~Gy} \mathrm{~s}^{-1}, \mathrm{pH}_{\text {initial }}=2.8$ and the temperature range 20$60{ }^{\circ} \mathrm{C}$ calculated at (a) 1 bar and (b) relative difference of equilibrium concentrations between 1 and 5 bar.

concentrations of $\mathrm{H}^{*}, \mathrm{e}_{\mathrm{aq}}{ }^{-}$and $\mathrm{OH}^{*}$ decrease by $20-50 \%$ when the pressure increases from 1 bar to 5 bar. Moreover, these graphs also indicate that the temperature influences the equilibrium concentrations of the radiolysis species (notice that the concentrations in Fig. 2a are on a logarithmic scale). Importantly, all of them exhibit the same decreasing trend with the temperature increase.

To estimate the influence of the radiolysis products on the precipitation/dissolution of Au the standard reduction potentials $v s$. standard hydrogen electrode (SHE) of the relevant halfcell reactions are listed in Table 1.

The reductive potentials $v s$. SHE using the Nernst equation for various in situ equilibrium conditions that are experimentally more relevant are additionally calculated. The average $E_{\text {NERNST }}$ was calculated for the following conditions: $\mathrm{pH}_{\text {initial }} 2.8$, dose rates $10^{6}$ to $10^{12} \mathrm{~Gy} \mathrm{~s}^{-1}$, temperature $20-60^{\circ} \mathrm{C}$. From the reductive potentials of the half cells for $\mathrm{Au}$ and different radiolysis products, it is clear that the Au species can be reduced in the presence of $\mathrm{e}_{\mathrm{aq}}{ }^{-}, \mathrm{H}^{\circ}, \mathrm{H}_{2} \mathrm{O}_{2}, \mathrm{HO}_{2}{ }^{-}, \mathrm{H}_{2}, \mathrm{HO}_{2}{ }^{\circ}, \mathrm{O}_{2}{ }^{--}$and can be oxidized in the presence of $\mathrm{OH}^{*}$ radicals. The strongest reducing agents are $\mathrm{e}_{\mathrm{aq}}{ }^{-}\left(E_{0}=-2.79 \mathrm{~V}_{\mathrm{SHE}}, E_{\mathrm{NERNST}}=-2.28 \pm 0.36 \mathrm{~V}_{\mathrm{SHE}}\right)$ and $\mathrm{H}^{*}\left(E_{0}=-2.23 \mathrm{~V}_{\mathrm{SHE}}, E_{\mathrm{NERNST}}=-2.09 \pm 0.15 \mathrm{~V}_{\mathrm{SHE}}\right)$, which cause rapid metal precipitation, ${ }^{39}$ while $\mathrm{OH}^{*}\left(E_{0}=1.83 \mathrm{~V}_{\mathrm{SHE}}\right.$, $E_{\text {NERNST }}=1.95 \pm 0.12 \mathrm{~V}_{\mathrm{SHE}}$, as a strong oxidative agent, causes metal dissolution. ${ }^{12}$ The reaction-rate coefficients between the radiolysis products and the Au species indicate that the $\mathrm{H}^{\circ}, \mathrm{OH}^{*}$ 
Table 1 Standard electrode and Nernst electrode potentials vs. SHE of the involved half-cell reactions

\begin{tabular}{|c|c|c|c|}
\hline Half cell & $E_{0}[\mathrm{~V}]$ & $E_{\text {NERNST }}[\mathrm{V}]$ & $\begin{array}{l}\text { Source } \\
E_{0}\end{array}$ \\
\hline $\mathrm{e}^{-}+\left[\mathrm{AuCl}_{2}\right]^{-} \rightleftharpoons \mathrm{Au}^{0}+2 \mathrm{Cl}^{-}$ & 1.15 & $0.97 \pm 0.03$ & 36 \\
\hline $\mathrm{e}^{-}+\mathrm{H}_{2} \mathrm{O} \rightleftharpoons \mathrm{e}_{\mathrm{aq}}^{-}$ & -2.79 & $-2.28 \pm 0.36$ & 26 \\
\hline $\mathrm{e}^{-}+\mathrm{H}^{+} \rightleftharpoons \mathrm{H}^{\cdot}$ & -2.23 & $-2.09 \pm 0.15$ & 26 \\
\hline $\mathrm{O}_{2}+\mathrm{H}^{+}+\mathrm{e}^{-} \rightleftharpoons \mathrm{HO}_{2}^{\cdot}$ & -0.04 & $-0.27 \pm 0.12$ & 27 \\
\hline $2 \mathrm{H}_{2} \mathrm{O}+2 \mathrm{e}^{-} \rightleftharpoons \mathrm{H}_{2}+2 \mathrm{OH}^{-}$ & -0.83 & $-0.26 \pm 0.42$ & 37 \\
\hline $2 \mathrm{H}^{+}+2 \mathrm{e}^{-} \rightleftharpoons \mathrm{H}_{2}$ & 0.00 & $-0.09 \pm 0.05$ & 37 \\
\hline $\mathrm{O}_{2}+\mathrm{e}^{-} \rightleftharpoons \mathrm{O}_{2}^{\cdot-}$ & -0.33 & $0.05 \pm 0.14$ & 27 \\
\hline $\mathrm{O}_{2}+2 \mathrm{H}^{+}+2 \mathrm{e}^{-} \rightleftharpoons \mathrm{H}_{2} \mathrm{O}_{2}$ & 0.70 & $0.49 \pm 0.12$ & 37 \\
\hline $\mathrm{O}_{2}^{-}+\mathrm{H}^{+}+\mathrm{e}^{-} \rightleftharpoons \mathrm{HO}_{2}^{-}$ & 1.02 & $0.65 \pm 0.16$ & 27 \\
\hline $\mathrm{O}_{2}+2 \mathrm{H}_{2} \mathrm{O}+4 \mathrm{e}^{-} \rightleftharpoons 4 \mathrm{OH}^{-}$ & 0.40 & $0.78 \pm 0.28$ & 37 \\
\hline $\mathrm{HO}_{2}{ }^{-}+\mathrm{e}^{-} \rightleftharpoons \mathrm{HO}_{2}^{-}$ & 0.73 & $0.88 \pm 0.24$ & 27 \\
\hline $\mathrm{O}_{2}^{\cdot-}+2 \mathrm{H}^{+}+\mathrm{e}^{-} \rightleftharpoons \mathrm{H}_{2} \mathrm{O}_{2}$ & 1.73 & $0.92 \pm 0.28$ & 27 \\
\hline $\mathrm{O}_{2}+2 \mathrm{H}^{+}+4 \mathrm{e}^{-} \rightleftharpoons 2 \mathrm{H}_{2} \mathrm{O}$ & 1.27 & $0.98 \pm 0.12$ & 37 \\
\hline $\mathrm{H}_{2} \mathrm{O}_{2}+2 \mathrm{H}^{+}+\mathrm{e}^{-} \rightleftharpoons 2 \mathrm{H}_{2} \mathrm{O}$ & 1.76 & $1.05 \pm 0.25$ & 37 \\
\hline $\mathrm{HO}_{2}^{\cdot}+\mathrm{H}^{+}+\mathrm{e}^{-} \rightleftharpoons \mathrm{H}_{2} \mathrm{O}_{2}$ & 1.46 & $1.18 \pm 0.13$ & 38 \\
\hline $\mathrm{OH}^{*}+\mathrm{e}^{-} \rightleftharpoons \mathrm{OH}^{-}$ & 1.83 & $1.95 \pm 0.12$ & 27 \\
\hline
\end{tabular}

Table 2 Reaction-rate constants of radiolysis products with gold species

\begin{tabular}{lllll}
\hline & $\begin{array}{l}\text { Radiolysis } \\
\text { spec. }\end{array}$ & $k_{20^{\circ} \mathrm{C}}\left[\mathrm{M}^{-1} \mathrm{~s}^{-1}\right]$ & $E_{\mathrm{A}}\left[\mathrm{kJ} \mathrm{mol}^{-1}\right]$ & $A_{\text {calculated }}$ \\
\hline $\mathrm{Au}^{+}$ & $\mathrm{e}_{\mathrm{aq}}{ }^{-}$ & $8.0 \times 10^{9}$ & 12.98 & $1.64 \times 10^{12}$ \\
& $\mathrm{H}^{*}$ & $8.0 \times 10^{9}$ & 15.09 & $3.91 \times 10^{12}$ \\
& $\mathrm{H}_{2} \mathrm{O}_{2}$ & 0 & 0 & 0 \\
& $\mathrm{HO}_{2}{ }^{-}$ & 1.89 & 25.8 & $7.46 \times 10^{4}$ \\
& $\mathrm{H}_{2}{ }^{-}$ & $7.4 \times 10^{-3}$ & 94.1 & $4.28 \times 10^{14}$ \\
& $\mathrm{HO}_{2}{ }^{-}$ & 1.89 & 25.8 & $7.46 \times 10^{4}$ \\
& $\mathrm{O}_{2}{ }^{-}$ & 1.89 & 25.8 & $7.46 \times 10^{4}$ \\
$\mathrm{Au}^{0}$ & $\mathrm{OH}^{-}$ & $1.83 \times 10^{9}$ & 13.0 & $3.80 \times 10^{11}$ \\
& & & &
\end{tabular}

radicals and $\mathrm{e}_{\mathrm{aq}}{ }^{-}$have a much stronger effect on the gold species compared to the other solutes (Table 2). More details about the interaction between the radiolysis products and the gold species in the liquid-cell TEM can be found in the ESI, Section 1.2.

Further explanation of the reaction rates can be found in the ESI, Table S3. $\dagger$

The primary aim of this study is to model and control the radical-induced redox chemistry in a liquid-cell TEM that is based on the precipitation/dissolution of Au NPs, which we used as a model system. Accordingly, we have simplified the model to a homogeneous system, which means the reduced $\mathrm{Au}$ species are introduced in the form of concentration and are all available for oxidation reactions. Additionally, it is assumed that all the $\mathrm{Au}$ ions are in the form of $\mathrm{Au}^{+}$, as we want to observe only the transition between the $\mathrm{Au}^{0}$ atoms and the $\mathrm{Au}^{+}$ions. The concentrations of $\mathrm{Au}$ species are incorporated into the model like any other component, where the reaction-rate constants between the radiolysis products and the Au species were taken from Table 2. The corresponding rate of Au-species production is shown in eqn (1):

$$
\frac{\mathrm{d} c_{\mathrm{Au}^{+}}}{\mathrm{d} t}=-\frac{\mathrm{d} c_{\mathrm{Au}^{0}}}{\mathrm{~d} t}=\sum_{i} k_{i-\mathrm{Au}^{0}} c_{i} c_{\mathrm{Au}^{0}}-\sum_{i} k_{i-\mathrm{Au}^{+}} c_{i} c_{\mathrm{Au}^{+}},
$$

where $c_{\mathrm{Au}^{+}}$and $c_{\mathrm{Au}^{0}}$ represent the concentrations of gold ions and gold atoms, respectively. The reaction-rate constants for the reactions between the $i$ compound with the gold species are indicated by $k_{i-\mathrm{Au}^{0}}$ and $k_{i-\mathrm{Au}^{+}}$. Using this equation, we estimated that the steady-state, i.e., the equilibrium, concentration of the gold species is achieved after $10^{-3} \mathrm{~s}$.

The resulting equilibrium ratio of $\left[\mathrm{Au}^{0}\right] /\left[\mathrm{Au}^{+}\right]$in our model can be taken as an indicator of the reductive/oxidative ratio between the ionic, i.e., dissolved, and the solid, i.e., precipitated, gold. The latter will form in the liquid cell as Au NPs. These theoretically obtained values can be translated into the LCTEM experiment by assuming that the Au precipitation or dissolution is directly related to the equilibrium ratio $\left[\mathrm{Au}^{0}\right] /$ $\left[\mathrm{Au}^{+}\right]$, thus providing the same kind of information. For example, a $\left[\mathrm{Au}^{0}\right] /\left[\mathrm{Au}^{+}\right]$gradient increase indicates the gold's tendency for precipitation and growth, resulting in the formation of $\mathrm{Au}$ NPs. In contrast, $\mathrm{a}\left[\mathrm{Au}^{0}\right] /\left[\mathrm{Au}^{+}\right]$gradient decrease signifies either the inability of Au to precipitate or the dissolution of the already-formed Au NPs. These are the phenomena that can be easily observed during LCTEM.

Temperature/Dose-rate Redox ratio (TDR) diagrams, showing different redox $\left[\mathrm{Au}^{0}\right] /\left[\mathrm{Au}^{+}\right]$stability regions, are shown in Fig. 3. The TDR diagrams are calculated for the dose-rate range $10^{6}$ to $10^{12} \mathrm{~Gy} \mathrm{~s}^{-1}$, temperature range $20-60^{\circ} \mathrm{C}$, and at the $\mathrm{H}_{2}+\mathrm{O}_{2}$ pressures $1 \mathrm{bar}, 3 \mathrm{bar}$, and $5 \mathrm{bar}$, with the molar ratio in the gaseous phase $\mathrm{H}_{2} / \mathrm{O}_{2}=2$. The resulting equilibrium redox concentration ratio of $\left[\mathrm{Au}^{0}\right] /\left[\mathrm{Au}^{+}\right]$was obtained for an initial concentration of $\mathrm{Au}^{+}$species of $1.5 \mathrm{mM}$ and a corresponding $\mathrm{pH}$ of 2.8. The calculated TDR diagrams are characterized with distinctive regions where the conditions in the liquid-cell TEM tend towards a reducing environment that will promote the precipitation of Au NPs (blue). In contrast, the oxidative environment (dark red) will either prevent the formation of Au NPs or promote the Au NPs' dissolution. The following "rainbow" color code indicates the intermediate conditions between the oxidative and reductive extremes.

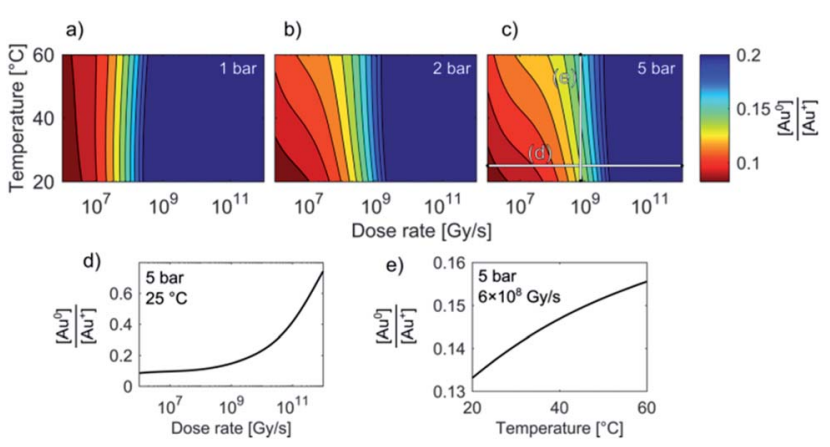

Fig. 3 TDR diagrams $(a-c)$. Note that the stability regions for the equilibrium $\left[\mathrm{Au}^{0}\right] /\left[\mathrm{Au}^{+}\right]$concentrations in the liquid-cell TEM are, in addition to dose-rate and temperature, also pressure dependent. Initial $\left[\mathrm{Au}^{+}\right]=1.5 \mathrm{mM}, \mathrm{pH}_{\text {initial }}=2.8$. (d) and (e) show sections of the Au redox ratio trends from diagram (c). 
When the pressure in the cell is set to 1 bar the temperature does not have any significant effect on the Au redox ratio (Fig. 3). In that case, a change in the dose rate has a much larger impact on the Au redox ratio when compared with a temperature change. This implies that the precipitation of gold is positively and monotonously correlated with an increase in the dose rate, as was previously reported by Schneider $e t$ al. ${ }^{11}$

However, our results indicate that even at intermediate dose rates the saturation concentration for the solubility of $\mathrm{H}_{2}$ and $\mathrm{O}_{2}$ in the aqueous solutions will be exceeded and the radiolysis model is better defined by considering the elevated-pressure regimes inside the LCTEM system. The resulting model at elevated pressure ( $5 \mathrm{bar}$ ) indicates that the effect of temperature on the Au redox ratio starts to become significant, which is most pronounced at the low and intermediate dose rates that are typically used during LCTEM. The effect of the temperature on the redox conditions can be explained by the scavenging effect of the $\mathrm{H}_{2}$ and $\mathrm{O}_{2}$ species, i.e., $\mathrm{H}_{2}$ is a strong $\mathrm{OH}^{-}$scavenger, while $\mathrm{O}_{2}$ is a strong scavenger of $\mathrm{H}^{-}$and $\mathrm{e}_{\mathrm{aq}}{ }^{-}$. Due to the presence of the gaseous phase, the concentrations of $\mathrm{H}_{2}$ and $\mathrm{O}_{2}$ are mainly dependent on the finite pressure and solubility limits. Moreover, with a temperature increase, the $\mathrm{O}_{2}$ solubility will decrease at higher rates when compared to the $\mathrm{H}_{2}$ solubility. As a result, a smaller amount of $\mathrm{H}^{*}$ and $\mathrm{e}_{\mathrm{aq}}{ }^{-}$scavengers at higher temperatures pushes the system toward more reductive conditions, as is evident in Fig. 3 for pressures of 3-5 bar. The sensitivity analysis of the temperature-dependent part of the $\mathrm{H}_{2}$ and $\mathrm{O}_{2}$ solubility supports this explanation and is elaborated in the ESI, Section 1.3. $\dagger$

In short, the change of the reaction-rate constants between the gold and the radiolysis species due to a temperature variation between $20{ }^{\circ} \mathrm{C}$ and $60{ }^{\circ} \mathrm{C}$ does not directly influence the gold redox ratio. The temperature change influences the maximum concentration of $\mathrm{O}_{2}$ and $\mathrm{H}_{2}$ in the liquid phase due to the thermodynamic solubility of these two gases. This effect is even more pronounced at higher pressures, as observed in Fig. 3a-c.

\section{Model verification by low-dose experiments using $\gamma$ radiation}

Prior to the LCTEM, the model was validated with a quantitative comparison using literature reports ${ }^{40-42}$ of radiolysis products obtained by irradiating water with low-dose $\gamma$ radiation. Electron radiation is a low-LET (linear energy transfer) radiation and is similar to $\gamma$ radiation. Hill ${ }^{43}$ calculated the primary yields for different electron energies and observed constant yields above $10 \mathrm{keV}$. Temperature-dependent primary yields were obtained for water at neutral $\mathrm{pH}$ from Elliot and Bartels. ${ }^{29}$ The experiments were performed at different dose rates and solute concentrations. Fig. 4 shows different sets of experimental $\mathrm{H}_{2} \mathrm{O}_{2}$ concentration data obtained by irradiating water with low-dose $\gamma$ radiation under various experimental conditions as a function of time. It is worth mentioning that every dataset is obtained from a different literature source. ${ }^{40-42}$ Only the experimental data for concentration variations of $\mathrm{H}_{2} \mathrm{O}_{2}, \mathrm{H}_{2}$ and $\mathrm{O}_{2}$ are reported here. More details about the model's verification can be found in the ESI, Table S6. $\dagger$ Individual experimental data points
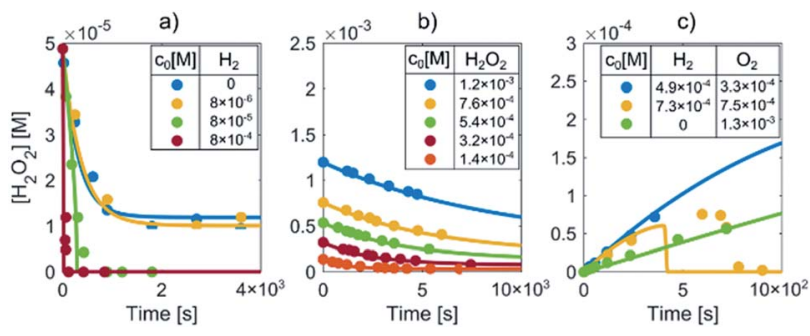

Fig. 4 Determination of $\mathrm{H}_{2} \mathrm{O}_{2}$ concentrations during the irradiation of water with low-dose $\gamma$ radiation for different initial (a) $\mathrm{H}_{2}$, (b) $\mathrm{H}_{2} \mathrm{O}_{2}$ and (c) $\mathrm{H}_{2}$ and $\mathrm{O}_{2}$ concentrations (marked by color-coded dots). The corresponding color-coded solid lines represent the prediction of our radiolysis model.

are represented by color-coded dots, while the corresponding color-coded solid lines are obtained from the kinetic radiolysis model developed in this study using the given low-dose $\gamma$ radiation experimental conditions. For example, Fig. 4a shows the concentration variations of $\mathrm{H}_{2} \mathrm{O}_{2}$ for different initial concentrations of $\mathrm{H}_{2}$, while Fig. $4 \mathrm{~b}$ shows $\mathrm{H}_{2} \mathrm{O}_{2}$ variations for different initial values of $\mathrm{H}_{2} \mathrm{O}_{2}$. Fig. 4c indicates the concentration changes of $\mathrm{H}_{2} \mathrm{O}_{2}$ when varying the initial concentration of both $\mathrm{H}_{2}$ and $\mathrm{O}_{2}$. Remarkably, although not at exactly the same time, our model accurately predicts the abrupt drop of the $\mathrm{H}_{2} \mathrm{O}_{2}$ concentration for the case of initial $\mathrm{H}_{2}$ and $\mathrm{O}_{2}$ concentrations of $7.31 \times 10^{-4}$ and $7.50 \times 10^{-5} \mathrm{M}$, respectively (shown in the yellow-coded color). By comparing the result of our kinetic radiolysis model with the experimental data for low-dose $\gamma$ radiation $\left(\sim 1 \mathrm{~Gy} \mathrm{~s}^{-1}\right),{ }^{40-42}$ it is evident that the proposed radiolysis model fits very well with the experimentally obtained data.

\section{Model verification based on Au precipitation/dissolution liquid-cell transmission electron microscopy (LCTEM)}

LCTEM was used to compare the observed Au NPs' precipitation, growth and dissolution dynamics with the calculated equilibrium $\mathrm{Au}$ redox ratio, $\left[\mathrm{Au}^{0}\right] /\left[\mathrm{Au}^{+}\right]$. First, the equilibrium conditions where the Au NPs were growing and dissolving at approximately the same rates were experimentally determined. Fig. 5 shows the time sequence of the precipitation and dissolution dynamics of the Au NPs at a constant dose rate of $10^{9} \mathrm{~Gy}$ $\mathrm{s}^{-1}$ and at a temperature of $20^{\circ} \mathrm{C}$. This absorbed dose rate was a result of a constant electron-beam exposure of approximately
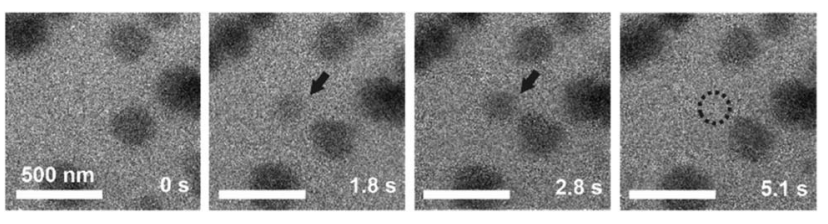

Fig. 5 TEM micrographs indicating the precipitation and dissolution of Au NPs at a constant dose rate of $10^{9} \mathrm{~Gy} \mathrm{~s}^{-1}$ and a temperature of $20{ }^{\circ} \mathrm{C}$. The encircled areas and arrows indicate the sequence of precipitation and dissolution for a single Au NP under equilibrium conditions. 
$200 \mathrm{e}^{-} \AA^{-2} \mathrm{~s}^{-1}$, assuming the $200 \mathrm{keV}$ electron stopping power in water (S) equal to $2.78 \mathrm{MeV} \mathrm{cm}^{2} \mathrm{~g}^{-1}$ and a density of $1 \mathrm{~g} \mathrm{~cm}^{-3}$. A representative region where the Au NPs exhibit precipitation, growth and dissolution on a time scale of $5 \mathrm{~s}$ is marked by an arrow or dashed-line circle. At $0 \mathrm{~s}$, the Au NPs are not yet formed; they appear at $1.8 \mathrm{~s}$ and remain stable for approximately $3 \mathrm{~s}$, followed by complete dissolution at $5.1 \mathrm{~s}$. The ex situ SAED analyses confirmed that the NPs are face-centered-cubic gold (ESI, Section $3 \uparrow$ ).

Knowing the experimentally determined $\left[\mathrm{Au}^{0}\right] /\left[\mathrm{Au}^{+}\right]$equilibrium conditions for this set of experiments, the proposed radiolysis model for radical-induced redox chemistry in a liquid-cell TEM by varying the electron dose rate at ambient temperature was further verified. The results of the experiment are shown in Fig. 6. The experimental dose rate was set to $10^{8} \mathrm{~Gy}$ $\mathrm{s}^{-1}$, corresponding to an electron-beam exposure of around 20 $\mathrm{e}^{-} \AA^{-2} \mathrm{~s}^{-1}$ for $4 \mathrm{~s}$ (Fig. 6a), just below the expected dose rate for the precipitation of Au NPs, as determined in the previous experiment. Accordingly, at a dose rate of $10^{8} \mathrm{~Gy} \mathrm{~s}^{-1}$ no NPs were formed. Then, after $4 \mathrm{~s}$ the dose rate was increased from $10^{8} \mathrm{~Gy} \mathrm{~s}^{-1}$ to $10^{12} \mathrm{~Gy} \mathrm{~s}^{-1}$ (beam exposure of around $2 \times 10^{5} \mathrm{e}^{-}$ $\AA^{-2} \mathrm{~s}^{-1}$ ) for $10 \mathrm{~s}$, which initiated the precipitation of Au NPs and their growth to an average size of $55 \mathrm{~nm}$ (Fig. 6b). The dose rate was then quickly reduced back to the initial $10^{8} \mathrm{~Gy} \mathrm{~s}^{-1}$, whereupon the Au NPs started to shrink, and in less than $10 \mathrm{~s}$ the NPs were completely dissolved (Fig. 6c). The experiment was repeated in the same area $110 \mathrm{~s}$ later to confirm that the phenomenon is repeatable. In this repeat experiment the area was exposed to a dose rate of $10^{12} \mathrm{~Gy} \mathrm{~s}^{-1}$ for $5 \mathrm{~s}$, instead of the $15 \mathrm{~s}$ in the previous experiment. The shorter exposure time resulted in the formation of NPs with an average size of $16 \mathrm{~nm}$ (Fig. 6d). When the dose rate was decreased for the second time to $10^{8} \mathrm{~Gy} \mathrm{~s}^{-1}$ the NPs dissolved in approximately $10 \mathrm{~s}$. A quantitative evaluation of the whole experiment is presented in Fig. 6e. It shows the variations in the size of the Au NPs as a function of the electron dose rate at room temperature. The line in the image represents the selected dose rate, while the circles indicate the average sizes of the NPs. These results

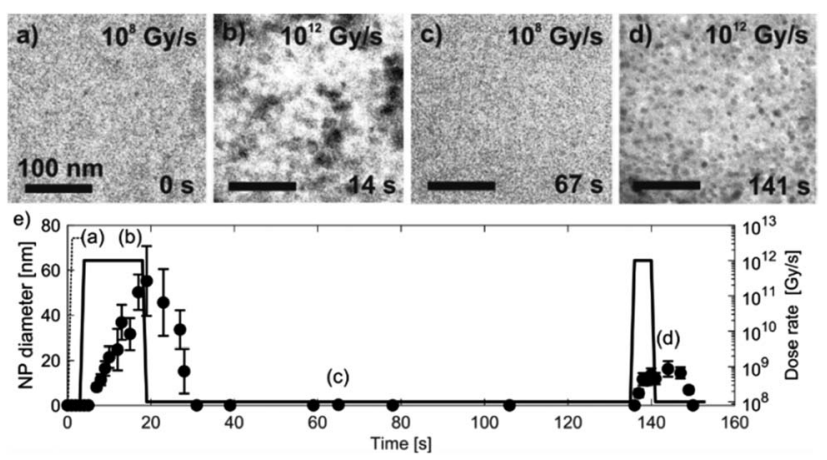

Fig. 6 Time-sequenced TEM micrographs acquired from the same specimen area at $25^{\circ} \mathrm{C}$ and alternating electron-dose rates (a) $10^{8}$, (b) $10^{12}$, (c) $10^{8}$ and (d) $10^{12} \mathrm{~Gy} \mathrm{~s}^{-1}$. (e) The corresponding graph of the Au NPs' precipitation and dissolution. The data points indicating the average NP diameters were determined from 10 individual NPs measured at a specific time. confirmed that the electron-dose-dependent LCTEM is reversible and correlates with the predictions of the TDR diagrams, where the Au NPs' precipitation or dissolution at an ambient temperature is positively correlated with the variations in the $\mathrm{Au}$ redox concentration ratio, i.e., $\left[\mathrm{Au}^{0}\right] /\left[\mathrm{Au}^{+}\right]$as a function of the electron dose rate. Similar precipitation/dissolution trends were observed in studies by Schneider et al. ${ }^{11}$ and Ahn et al. ${ }^{16}$

Fig. 7 shows TEM micrographs of the precipitation/ dissolution of the Au NPs as a function of temperature between $25{ }^{\circ} \mathrm{C}$ and $40{ }^{\circ} \mathrm{C}$ over a period of $1200 \mathrm{~s}$. The electron dose rate was fixed at $6 \times 10^{8} \mathrm{~Gy} \mathrm{~s}^{-1}$, at an initial temperature of $25{ }^{\circ} \mathrm{C}$, just below the experimentally determined boundary conditions for the Au NPs' precipitation. The temperaturedependent experiment started at $25{ }^{\circ} \mathrm{C}$, with the same specimen area being observed for $215 \mathrm{~s}$ (Fig. 7a), which is several orders of magnitude longer than the time needed to reach the equilibrium concentration of radiolysis species. This experiment demonstrates that the Au-based aqueous solution is stable at electron-dose rates of around $10^{8} \mathrm{~Gy} \mathrm{~s}^{-1}$ at $25^{\circ} \mathrm{C}$. Then, after a relatively long exposure time, the temperature was increased to $30{ }^{\circ} \mathrm{C}$ for a period of $110 \mathrm{~s}$. These conditions did not result in any precipitation of Au NPs, in accordance with the relatively broad $\left[\mathrm{Au}^{0}\right] /\left[\mathrm{Au}^{+}\right]$gradient field in the temperature domain, as indicated in the TDR diagrams for elevated pressures. Next, the temperature was increased to $40{ }^{\circ} \mathrm{C}$ for $\Delta t=$ $110 \mathrm{~s}$, and the Au NPs started to form with an average diameter of approximately $25 \mathrm{~nm}$ (Fig. 7b). Then, when the temperature was decreased to $25{ }^{\circ} \mathrm{C}$ these precipitated Au NPs were completely dissolved in approximately $100 \mathrm{~s}$ (Fig. 7c).

The reversibility of the phenomenon was checked by repeating the temperature changes. First, the temperature was set to $40{ }^{\circ} \mathrm{C}$ for $\Delta t=160 \mathrm{~s}$, which resulted in the precipitation of $\mathrm{Au}$ NPs with an average diameter of approximately $30 \mathrm{~nm}$ (Fig. 7d), after which the temperature was reduced to $25^{\circ} \mathrm{C}$ and the previously precipitated Au NPs were again completely dissolved (Fig. 7e). In this way we were able to confirm the temperature-dependent reversibility of the Au precipitationdissolution mechanism. The corresponding graph of the

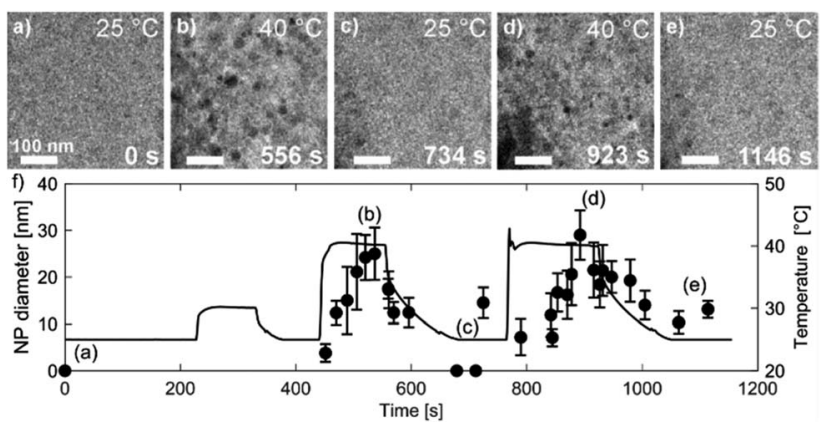

Fig. 7 Time-sequenced TEM micrographs acquired from the same specimen area at a fixed electron-dose rate of $6 \times 10^{8} \mathrm{~Gy} \mathrm{~s}^{-1}$ and alternating temperatures of (a) $25^{\circ} \mathrm{C}$, (b) $40^{\circ} \mathrm{C}$, (c) $25^{\circ} \mathrm{C}$, (d) $40^{\circ} \mathrm{C}$ and (e) $25^{\circ} \mathrm{C}$. (f) Corresponding graph of the Au NPs' precipitation and dissolution. The temperature-time profile is shown as a black line. The data points indicating the average NP diameters came from 10 NPs measured at a specific time. 
temperature-dependent Au NPs' precipitation and dissolution behavior in the TEM images is shown in Fig. $7 \mathrm{f}$.

These observations are in contrast to what we would expect to see in a conventional experiment, i.e., neglecting the radiolysis-induced redox chemistry, where the precipitation of $\mathrm{Au}$ NPs from an aqueous solution at low $\mathrm{pH}$ values is provoked by elevated temperature. ${ }^{44,45}$ Furthermore, such a process is not reversible and cannot lead to Au NPs dissolving as the temperature drops. This phenomenon can only be explained in terms of the temperature changes modifying the equilibrium concentration of the radiolysis species, thereby changing the $\mathrm{Au}$ redox concentration ratios, finally resulting in the reversible precipitation/dissolution of Au NPs. These results are therefore consistent with the $\left[\mathrm{Au}^{0}\right] /\left[\mathrm{Au}^{+}\right]$trends indicated in the TDR diagrams for elevated pressures (Fig. 3c).

\section{Experimental section}

The extensive simulation algorithms for the radiolysis inside the liquid-cell TEM were built in the MATLAB software platform (MATLAB 2016b, The MathWorks, Inc., Natick, Massachusetts, United States).

An aerated $1.5 \mathrm{mM}$ water solution of gold(III) chloride trihydrate (chloroauric acid) as a source of gold was used (Sigma Aldrich, $>99.9 \%$ trace-metal basis). The solution was prepared a few minutes before the start of the experiments to avoid any potential spontaneous Au NP formation. Different sets of LCTEM experiments were performed at various electron-dose rates and temperatures, focused on precipitation and dissolution of the Au NPs.

The TEM (Jeol JEM 2100 TEM) operated at a $200 \mathrm{kV}$ accelerating voltage had a Protochips Poseidon liquid holder with a heating capability (Protochips Inc., Raleigh, NC). Experimental images and videos were recorded using an Orius Model 832 SC1000 CCD camera at 30 frames per second and a theoretical pixel resolution of $0.5 \mathrm{~nm}$. The TEM observation mode was selected to achieve a uniform and parallel illumination of the analyzed area with the electron beam. The electron-dose rate for given electron-optical TEM parameters was calculated according to the expression developed by Schneider $e t$ al. ${ }^{11}$ (ESI, eqn $S(3) \dagger)$. The electron density for the specimen area, an important parameter for determining the electron-dose rate for a thin liquid layer, was controlled by various combinations between initial gun current, condenser lens and condenser aperture settings in the TEM. The aqueous solution inside the holder was confined in a closed cell between the two silicon chips (referred to as the top and bottom chips). Imaging was performed on the exit side of the bottom chip, in the corner areas of two SiN crossed windows, separated by $50 \mathrm{~nm}$-thick spacers, resulting in a relatively controlled water-layer thickness with minimized window bulging in the area of observation and relatively high theoretical spatial resolution in the sub-nm range. ${ }^{23}$ The top chip contains tungsten heating coils for the external heating of the liquid. Special care was taken in order to prevent any dust entering the chips. ${ }^{2}$

The temperature of the aqueous solutions in the liquid cell was regulated indirectly by applying an electric current through the tungsten coils located on the top chip. The electrical current was applied with a Keithley controller via Protochips Poseidon V2.0.4 software (Protochips Inc., Raleigh, NC) with a calibration curve that was provided by the manufacturer. With this system, a temperature between $20^{\circ} \mathrm{C}$ and $100^{\circ} \mathrm{C}$ could be achieved. In this study the heating rate was $5{ }^{\circ} \mathrm{C} \mathrm{s}^{-1}$, with the maximum temperature set to $60^{\circ} \mathrm{C}$. The temperature increase of the liquid as a result of the electron-beam irradiation was not taken into consideration, as it was shown in several studies that for the given experimental beam currents the temperature rise is restricted to within a few degrees centigrade..$^{17,22}$ The fastest cooling rate from the final temperature $\left(\approx 60^{\circ} \mathrm{C}\right)$ was estimated to be around $0.6{ }^{\circ} \mathrm{C} \mathrm{s}^{-1}$. The morphology, composition and crystal structure of the precipitates that were formed during the in situ LCTEM were subsequently analyzed in a dried state using a conventional TEM, for example, the selected-area electron diffraction (SAED) analysis and energy-dispersive X-ray spectroscopy (EDXS).

\section{Conclusions}

The proposed TDR diagrams obtained from the improved kinetic radiolysis model provide us with a better simulation of the precipitation, growth and dissolution of Au NPs under a variety of LCTEM conditions. In the LCTEM system the Au redox potential is investigated as a parameter of the electrondose rate, temperature and pressure. Our new model was verified using experimental literature data obtained from low-dose experiments using $\gamma$ radiation. The validity of the radiolysis model was then confirmed by LCTEM experiments that were consistent with the TDR diagrams. It was confirmed that the $\mathrm{Au}$ NPs precipitate firstly as a result of an increased dose rate and, secondly, due to the combined effect of the increased temperature, pressure and saturation concentration of $\mathrm{H}_{2}$ and $\mathrm{O}_{2}$, which in both cases shift the equilibrium $\left[\mathrm{Au}^{0}\right] /\left[\mathrm{Au}^{+}\right]$concentrations in favor of zero-valence gold $\left(\mathrm{Au}^{0}\right)$. Both proposed mechanisms were found to be completely reversible, which suggests that the Au precipitation/dissolution reactions can be fine tuned by altering the parameters inside the liquid-cell TEM.

Modeling the complex redox chemistry inside the liquid-cell TEM allows a real-time nanoscale visualization and manipulation of nanostructured systems in liquid environments. As such, our radiolysis model can, in principle, be implemented in many different branches of nanotechnology and energy-related processes by including appropriate, system-specific, radicalinduced redox chemistry.

\section{Conflicts of interest}

There are no conflicts to declare.

\section{Acknowledgements}

This research was financially supported by Slovenian Research Agency (research core funding No. P2-0084 and P2-0152 and Project Z2-8161). Additional funding was received from the European Union's Horizon 2020 research and innovation 
programme under grant agreements No. 823717-ESTEEM3 and No. 674973-DEMETER. We are grateful to Protochips Inc., Raleigh, NC, for providing the silicon heating chips.

\section{Notes and references}

1 F. M. Ross, Opportunities and Challenges in Liquid Cell Electron Microscopy, Science, 2015, 350, aaa9886.

2 J. Hermannsdörfer and N. de Jonge, Studying Dynamic Processes of Nano-Sized Objects in Liquid Using Scanning Transmission Electron Microscopy, J. Visualized Exp., 2017, 54943.

3 J. M. Yuk, J. Park, P. Ercius, K. Kim, D. J. Hellebusch, M. F. Crommie, J. Y. Lee, A. Zettl and A. P. Alivisatos, High-Resolution EM of Colloidal Nanocrystal Growth Using Graphene Liquid Cells, Science, 2012, 336, 61-64.

4 N. D. Loh, S. Sen, M. Bosman, S. F. Tan, J. Zhong, C. A. Nijhuis, P. Král, P. Matsudaira and U. Mirsaidov, Multistep Nucleation of Nanocrystals in Aqueous Solution, Nat. Chem., 2017, 9, 77-82.

5 M. R. Hauwiller, X. Zhang, W.-I. Liang, C.-H. Chiu, Q. Zhang, W. Zheng, C. Ophus, E. M. Chan, C. Czarnik, M. Pan, et al., Dynamics of Nanoscale Dendrite Formation in Solution Growth Revealed Through in Situ Liquid Cell Electron Microscopy, Nano Lett., 2018, 18, 6427-6433.

6 X. Chen and J. Wen, In Situ Wet-Cell TEM Observation of Gold Nanoparticle Motion in an Aqueous Solution, Nanoscale Res. Lett., 2012, 7, 598.

7 J. H. Park, D. A. Steingart, S. Kodambaka and F. M. Ross, Electrochemical Electron Beam Lithography: Write, Read and Erase Metallic Nanocrystals on Demand, Sci. Adv., 2017, 3, e1700234.

8 G. Zhu, Y. Jiang, F. Lin, H. Zhang, C. Jin, J. Yuan, D. Yang and Z. Zhang, In Situ Study of the Growth of Two-Dimensional Palladium Dendritic Nanostructures Using Liquid-Cell Electron Microscopy, Chem. Commun., 2014, 50, 9447-9450.

9 M. H. Nielsen, S. Aloni and J. J. De Yoreo, In Situ TEM Imaging of $\mathrm{CaCO}_{3}$ Nucleation Reveals Coexistence of Direct and Indirect Pathways, Science, 2014, 345, 1158-1162.

10 M. S. A. Asghar, B. J. Inkson and G. Möbus, Giant Radiolytic Dissolution Rates of Aqueous Ceria Observed In Situ by Liquid-Cell TEM, ChemPhysChem, 2017, 18, 1247-1251.

11 N. M. Schneider, M. M. Norton, B. J. Mendel, J. M. Grogan, F. M. Ross, H. H. Bau, M. Frances and H. H. Bau, ElectronWater Interactions and Implications for Liquid Cell Electron Microscopy, J. Phys. Chem. C, 2014, 118, 22373-22382.

12 D. Alloyeau, W. Dachraoui, Y. Javed, H. Belkahla, G. Wang, H. H. Lecoq, S. Ammar, O. Ersen, A. Wisnet, F. Gazeau, et al., Unravelling Kinetic and Thermodynamic Effects on the Growth of Gold Nanoplates by Liquid Transmission Electron Microscopy, Nano Lett., 2015, 15, 2574-2581.

13 Y. C. Chen, J. Y. Chen and W. W. Wu, In Situ Observation of $\mathrm{Au}$ Nanostructure Evolution in Liquid Cell TEM, J. Phys. Chem. C, 2017, 121, 26069-26075.

14 Y. Liu, X. M. Lin, Y. Sun and T. Rajh, In Situ Visualization of Self-Assembly of Charged Gold Nanoparticles, J. Am. Chem. Soc., 2013, 135, 3764-3767.
15 H.-G. Liao and H. Zheng, Liquid Cell Transmission Electron Microscopy Study of Platinum Iron Nanocrystal Growth and Shape Evolution, J. Am. Chem. Soc., 2013, 135, 5038-5043.

16 T.-Y. Ahn, S.-P. Hong, S.-I. Kim and Y.-W. Kim, In Situ LiquidCell Transmission Electron Microscopy for Direct Observation of Concentration-Dependent Growth and Dissolution of Silver Nanoparticles, RSC Adv., 2015, 5, 82342-82345.

17 R. F. Egerton, P. Li and M. Malac, Radiation Damage in the TEM and SEM, Micron, 2004, 35, 399-409.

18 P. Abellan, T. J. Woehl, L. R. Parent, N. D. Browning, J. E. Evans and I. Arslan, Factors Influencing Quantitative Liquid (Scanning) Transmission Electron Microscopy, Chem. Commun., 2014, 50, 4873-4880.

19 T. J. Woehl, J. E. Evans, I. Arslan, W. D. Ristenpart and N. D. Browning, Direct in Situ Determination of the Mechanisms Controlling Nanoparticle Nucleation and Growth, ACS Nano, 2012, 6, 8599-8610.

20 C. Wadell, S. Inagaki, T. Nakamura, J. Shi, Y. Nakamura and T. Sannomiya, Nanocuvette: A Functional Ultrathin Liquid Container for Transmission Electron Microscopy, ACS Nano, 2017, 11, 1264-1272.

21 J. H. Park, N. M. Schneider, J. M. Grogan, M. C. Reuter, H. H. Bau, S. Kodambaka and F. M. Ross, Control of Electron Beam-Induced $\mathrm{Au}$ Nanocrystal Growth Kinetics through Solution Chemistry, Nano Lett., 2015, 15, 53145320 .

22 J. M. Grogan, N. M. Schneider, F. M. Ross and H. H. Bau, Bubble and Pattern Formation in Liquid Induced by an Electron Beam, Nano Lett., 2014, 14, 359-364.

23 N. de Jonge and F. M. Ross, Electron Microscopy of Specimens in Liquid, Nat. Nanotechnol., 2011, 6, 695-704.

24 T. J. Woehl, K. L. Jungjohann, J. E. Evans, I. Arslan, W. D. Ristenpart and N. D. Browning, Experimental Procedures to Mitigate Electron Beam Induced Artifacts during in Situ Fluid Imaging of Nanomaterials, Ultramicroscopy, 2013, 127, 53-63.

25 A. Mozumder, Interaction of Radiation with Matter: Energy Transfer from Fast Charged Particles, in Fundamentals of Radiation Chemistry, Academic Press, San Diego, California, 1999, pp. 1-4.

26 G. V. Buxton, C. L. Greenstock, W. P. Helman and A. B. Ross, Critical Review of Rate Constants for Reactions of Hydrated Electrons, Hydrogen Atoms and Hydroxyl Radicals in Aqueous Solution, J. Phys. Chem. Ref. Data, 1988, 17, 513886.

27 H. A. Schwarz, Free Radicals Generated by Radiolysis of Aqueous Solutions, J. Chem. Educ., 1981, 58, 101-105.

28 D. Bhattacharya, M. Bosman, V. R. S. S. Mokkapati, F. Y. Leong and U. Mirsaidov, Nucleation Dynamics of Water Nanodroplets, Microsc. Microanal., 2014, 20, 407-415.

29 A. J. Elliot and D. M. Bartels, The Reaction Set, Rate Constants and $g$-Values for the Simulation of the Radiolysis of Light Water over the Range $20^{\circ}$ to $350^{\circ} \mathrm{C}$ Based on Information Available in 2008, Report AECL No. 153-127160-450-001, Atomic Energy of Canada Ltd., Mississauga, Ontario, Ca, 2009. 
30 D. Shin, J. B. Park, Y.-J. Kim, S. J. Kim, J. H. Kang, B. Lee, S. P. Cho, B. H. Hong and K. S. Novoselov, Growth Dynamics and Gas Transport Mechanism of Nanobubbles in Graphene Liquid Cells, Nat. Commun., 2015, 6, 6068.

31 G. Zhu, Y. Jiang, W. Huang, H. Zhang, F. Lin and C. Jin, Atomic Resolution Liquid-Cell Transmission Electron Microscopy Investigations of the Dynamics of Nanoparticles in Ultrathin Liquids, Chem. Commun., 2013, 49, 10944-10946.

32 C. L. Young, Volume 5/6, Hydrogen and Deuterium, in IUPAC-NIST Solubility Database, Pergamon Press, Oxford, U.K., 1981, pp. 1-3.

33 R. Battino, Volume 7, Oxygen and Ozone, in IUPAC-NIST Solubility Database, Pergamon Press, Oxford, U.K., 1981, pp. 1-5.

34 H. L. Xin, K. Niu, D. H. Alsem and H. Zheng, In Situ TEM Study of Catalytic Nanoparticle Reactions in Atmospheric Pressure Gas Environment, Microsc. Microanal., 2013, 19, 1558-1568.

35 T. Ngo and H. Yang, Toward Ending the Guessing Game: Study of the Formation of Nanostructures Using in Situ Liquid Transmission Electron Microscopy, J. Phys. Chem. Lett., 2015, 6, 5051-5061.

36 J. J. Lingane, Standard Potentials of Half-Reactions Involving +1 and +3 Gold in Chloride Medium: Equilibrium Constant of the Reaction $\mathrm{AuCl}_{4}{ }^{-}+2 \mathrm{Au}+2 \mathrm{Cl}^{-}=3 \mathrm{AuCl}_{2}{ }^{-}, \mathrm{J}$. Electroanal. Chem., 1962, 4, 332-342.

37 G. S. Bratsch, Standards Electrode Potentials and Temperature Coefficients in Water at $298.15 \mathrm{~K}$, J. Phys. Chem. Ref. Data, 1989, 18, 1-21.
38 D. A. Armstrong, R. E. Huie, S. Lymar, W. H. Koppenol, G. Merényi, P. Neta, B. Ruscic, D. M. Stanbury and S. Steenken, Standard Electrode Potentials Involving Radicals in Aqueous Solution: Inorg anic Radicals (IUPAC Technical Report), Pure Appl. Chem., 2015, 87, 1139-1150.

39 A. S. Ghosh Mazumdar and E. J. Hart, A Pulse Radiolysis Study of Bivalent and Zerovalent Gold in Aqueous Solutions, in Radiation Chemistry, ed. E. J. Hart, American Chemical Society, 1968, pp. 193-209.

40 B. Pastina and J. A. Laverne, Effect of Molecular Hydrogen on Hydrogen Peroxide in Water Radiolysis, J. Phys. Chem. A, 2001, 105, 9316-9322.

41 E. Hayon, Radiolysis of Air-Free Aqueous Solutions of Hydrogen Peroxide, Trans. Faraday Soc., 1964, 60, 10591067.

42 C. J. Hochanadel, Effects of Cobalt $\gamma$-Radiation on Water and Aqueous Solutions, J. Phys. Chem., 1952, 56, 587-594.

43 M. A. Hill and F. A. Smith, Calculation of Initial and Primary Yields in the Radiolysis of Water, Radiat. Phys. Chem., 1994, 43, 265-280.

44 J. Turkevich, P. C. Stevenson and J. Hillier, A Study of the Nucleation and Growth Processes in the Synthesis of Colloidal Gold, Discuss. Faraday Soc., 1951, 11, 55-75.

45 M. Wuithschick, A. Birnbaum, S. Witte, M. Sztucki, U. Vainio, N. Pinna, K. Rademann, F. Emmerling, R. Kraehnert and J. Polte, Turkevich in New Robes: Key Questions Answered for the Most Common Gold Nanoparticle Synthesis, ACS Nano, 2015, 9, 7052-7071. 